\title{
Comparative study of long segment versus short segment posterior fixation of thoracolumbar fractures with pedicle
}

\section{screws}

\author{
Vihar S Joshi ${ }^{1}$, Naveen DS ${ }^{1,{ }^{*}}$, and Nilesh Kumar Agrawal ${ }^{1}$ \\ ${ }^{1}$ Department of Orthopedics, Jagadguru Jayadeva Murugarajendra Medical College (JJMMC), Davanagere, Karnataka-577004, India
}

\begin{abstract}
Choice of long or short segment fixation for thoracolumbar fractures, benefits of either of these techniques has been a topic for analysis and assessment. Kyphotic angles in twenty patients diagnosed to have thoracolumbar vertebral fractures between December 2019 to December 2020 in Bapuji hospital and Chigateri general hospital, Davanagere, Karnataka, India were measured pre operatively, post operatively and at one year follow up and assessed. No statistical difference between the degrees of correction of initial kyphotic angle between long segment fixation and short segment posterior fixation in our study was found $(p<0.6)$. Method of fixation of the thoracolumbar vertebral fracture did not correlate with initial degree of kyphosis $(p=0.4)$. Amount of correction loss at one year follow up was found to be statistically significant in short segment fixation $(\mathrm{p}<0.05)$. Loss of kyphotic angle at one year follow up was higher in case of short segment fixation than long segment fixation and found to be statistically significant $(\mathrm{p}<0.005)$. Our study showed that long segment fixation helps in better correction of the kyphosis angle with lesser chance of loss of correction and can be opted when pedicles aren't intact at the fracture level, as in cases of burst fractures. Short segment fixation provides better rigid fixation at the site of fracture with increased range of motion at the thoracolumbar segment and can be treatment of choice when the pedicles at the fractured level are intact, as in cases of compression fractures, having benefits of shorter duration of surgery and reduced risks.
\end{abstract}

Keywords: thoracolumbar fractures; long segment posterior; short segment posterior; pedicle screw; posterior spine

*Corresponding author: Dr. Naveen DS, Assistant Professor, Department of Orthopedics, Jagadguru Jayadeva Murugarajendra Medical College (JJMMC), Davanagere, Karnataka-577004, India. Mobile: +919986091144; Email: nds5959@gmail.com

Received 4 February 2021; Revised 16 March 2021; Accepted 22 March 2021; Published 31 March 2021

Citation: Vihar SJ, Naveen DS, Agrawal NK. Comparative study of long segment versus short segment posterior fixation of thoracolumbar fractures with pedicle screws. J Med Sci Res. 2021; 9(2):77-84. DOI: http://dx.doi.org/10.17727/JMSR.2021/9-12

Copyright: (c) 2021 Vihar SJ et al. Published by KIMS Foundation and Research Center. This is an open-access article distributed under the terms of the Creative Commons Attribution License, which permits unrestricted use, distribution, and reproduction in any medium, provided the original author and source are credited. 


\section{Introduction}

The second most commonly involved spinal segment injuries after cervical segment is the thoracolumbar spinal segment, about 30 to $60 \%$ of all spinal injuries. $60 \%$ of thoracolumbar injuries in trauma are concentrated between T12 and L2 vertebrae [1]. This motion segment connects the relatively rigid, kyphotic thoracic spine which is stabilized by the rib cage to the more mobile lordotic lumbar vertebrae. Substantial biomechanical stress during traumatic incidents between this transitional zone having differential mobility makes it susceptible to fracture. Many authors advised non operative treatment for the fracture of thoracolumbar vertebral fractures but later report emphasized the advantage of open reduction internal fixation with posterior instrumentation [2, 3]. Surgical options include an anterior approach, a posterior approach, or a combined antero-posterior approach. Each surgical option has unique advantages and disadvantages. Generally, the best approaches used are the anterior approach used at the level of thoracolumbar junction. Low lumbar injuries can be treated by posterior approach usually resulting in spinal cord injuries. Antero-posterior surgeries typically are reserved for highly unstable fracture subluxations [4]. As most orthopedic and spinal surgeons are more experienced in posterior approach and at the same time this approach and involves less operative time and less blood loss is considered be a safer approach [5].

Roy-Camille et al [6] introduced pedicle screws for treatment of thoracolumbar fractures in 1963. Dick et al [7] further developed this technique in 1985. One of the most fundamental considerations is whether to instrument only the anterior column, the posterior column, or both. Once this decision is made, the surgeon must chose a construct for the posterior instrumentation, and this decision is made based on the level of the fracture, the pattern of comminution, extent of instability, neural status. Unstable thoracic compression and burst fractures will inevitably tend to collapse into further kyphosis, and should be instrumented with a long fixation construct capable of resisting these deforming forces [8]. Harrington rod and drummond wires can be used successfully, but contemporary fixation more commonly consists of segmental rod-hook or rod-screw constructs. In either case, the old rule of "three-above, two-below" may be followed, but evidence suggests that pedicle screw fixation will prove successful with shorter constructs. Initially, long segment pedicle screw fixation that involved at least two levels above and below the fractured vertebra was most frequently used surgical fixation method that promoted early ambulation and improving the kyphosis of the spine $[9,10]$. Less rate of failure, yet significant increased vertebral immobility, dorsalgia and implant failure were detected in long segment fixation [11-14].

Raising concerns about reduced or loss of motion segments with long segment fixation, short segment fixation technique, which uses fixation of the fracture at level one above and one level below, were used [15-18]. Short segment pedicle screw fixation techniques were popularized since 1985 [7]. Short segment instrumentation limits the number of segments instrumented to the very minimum necessary to restore sagittal balance and stabilize the fracture. Pedicle screw fixation allows surgeons to stop their fixation constructs in the upper lumbar spine and avoid interference with mid- and lower lumbar motion segments. Short-segment posterior fixation including the fractured level (SSPI) rigidly fixes short segments of the thoracolumbar spine, providing sagittal, axial, and torsional stability superior to rod/hook constructs or sub laminar wiring $[19,20]$.

An et al, in a biomechanical study of L2 burst fractures, found that in short constructs, the fixation provided by pedicle screws is superior in all planes to that provided by hooks [21] obtaining purchase in all three vertebral columns through a single dorsal approach. No difference in stiffness of the construct between long segment and shortsegment pedicle screw constructs were noted. Short segment posterior instrumentation allows direct reduction of sagittal deformity and translation while immobilizing the shortest possible segment of the lumbar spine. Thoracolumbar and lumbar fractures are treated with pedicle screws placed immediately above and below the fractured segment. Ebelke et al found that transpedicular bone grafting, performed after manually elevating the fractured endplate and restoring vertebral height, eliminated pedicle screw failure in their series [22]. The short segment pedicle screw fixation was also found to have its own pitfalls such as inadequate stability of the spine, high chances or unacceptable rates of implant failure 
along with kyphosis correction loss postoperatively [10, 23-27].

Based on personal experiences, few of the authors suggested that the pedicle screw placement at the level of the fractured vertebrae increased load sharing ability and stability of the construct [14, 15] though it has still been indeterminate whether long segment fixation is more effective and preferable than short segment fixation. It is purpose of this study to compare between the long segment and short segment posterior fixation of lumbar vertebral fracture with pedicle screws in terms of correction of deformity, extent to which they maintain correction and postoperative loss of correction between them.

\section{Methodology}

The study was conducted in twenty patients in Bapuji medical college and Chigateri general hospital, Davanagere, Karnataka between December 2019 to December 2020. Patients who presented to outpatient department and casualty with history of trauma were clinically examined, diagnosed with fractures in thoracolumbar region of the spine with help of X-ray and CT scan.

Inclusion criteria: (a) Patients aged >20 and < 50years, (b) Single level traumatic A0 type A T11-L2 vertebral fractures.

Exclusion criteria: (a) Multiple level thoracolumbar vertebral fractures, (b) AO type A0 Thoracolumbar vertebral fractures, (c) Patients with severe comorbidity and unfit for general anesthesia, (d) Reverse transcription-polymerase chain reaction (RTPCR) positive patients for coronavirus disease 2019 (COVID-19).

Assessment of pedicle intactness, direction of the screw and also screw sizes before the procedure were done based on which twelve patients underwent long segment fixation using pedicle screws at 2 levels above and 2 levels below the fractured vertebrae. Eight patients underwent short segment fixation posterior fixation based on the X-ray and computerized tomography (CT) scan after assessing the intactness of the pedicle of the fractured vertebrae and ability to place pedicle screw bilaterally at the fractured vertebrae safely. Kyphotic angle of the spine was measured using Cobb's method. X-rays were also taken immediate post operatively and at time of one year post-operative follow up and assessment of preoperative, immediate postoperative and one year postoperative kyphotic angles; preoperative, immediate postoperative and one year postoperative kyphotic angle changes were done and statistically analyzed using SPSS version 19.

\section{Results}

Total of 20 patients were included in the study. Mean age group of study was 29.8 years (21-41). Maximum of 7 patients (35\%) belonged to age group between $25-29$ followed by 6 patients (30\%) between 30-34; 3 patients (15\%) between 20-24 and 35-39 each. Only one patient (5\%) belonged to age group 40-44. Male to female ratio was found to be 13:7 (Table 1).

Table 1: Age and sex wise distribution of patients in the study.

\begin{tabular}{|ccc|}
\hline Age (Years) & Male & Female \\
\hline $20-24$ & 2 & 1 \\
$25-29$ & 5 & 2 \\
$30-34$ & 4 & 2 \\
$35-39$ & 1 & 2 \\
$40-44$ & 1 & 0 \\
\hline
\end{tabular}

Single level thoracolumbar vertebral fractures were considered for study and highest of 9 patients (45\%) had AO type A2 thoracolumbar vertebral fracture. 7 patients (35\%) had A0 type A3 fractures, 2 patients (10\%) had A0 type A1 and A4 thoracolumbar vertebral fractures each. Long segment fixation was done in 7 patients with AO type A3 fracture, followed by 2 patients with type A4 fracture, 2 patients with AO type A2 and one patient with AO type A1 fracture. Short segment fixation was done in 7 patients with AO type A2 fracture and 1 patient with AO type A1 fracture. Total of 8 male patients and 4 female patients underwent long segment fixation; 5 male and 3 female patients underwent Short segment posterior fixation (Table 2).

The mean preoperative kyphotic angle of patients was found to be $22.85^{\circ}$ and ranged from $18-30^{\circ}$. The mean preoperative kyphotic angle of patients who underwent long segment fixation was $23.58^{\circ}$ $\left(18-30^{\circ}\right)$ and $21.75^{\circ}\left(18-38^{\circ}\right)$ in patients who were operated with short segment fixation. Immediate post-operative $\mathrm{X}$-rays showed reduction of kyphotic angle in patients who underwent long segment 
Table 2: Type of thoracolumbar fractures in the study with method of fixation done in each patient.

\begin{tabular}{|c|c|c|c|c|c|c|c|c|}
\hline \multirow{3}{*}{ Method of fixation } & \multicolumn{8}{|c|}{ AO type of Thoracolumbar vertebral fracture } \\
\hline & \multicolumn{2}{|c|}{$A 1$} & \multicolumn{2}{|c|}{$A 2$} & \multicolumn{2}{|c|}{$A 3$} & \multicolumn{2}{|c|}{$A 4$} \\
\hline & Male & Female & Male & Female & Male & Female & Male & Female \\
\hline Long segment & 0 & 1 & 1 & 1 & 6 & 1 & 1 & 1 \\
\hline Short segment & 1 & 0 & 4 & 3 & 0 & 0 & 0 & 0 \\
\hline
\end{tabular}

posterior fixation to a mean of $6.16^{\circ}\left(4-9^{\circ}\right)$ and to $6.75^{\circ}\left(5-8^{\circ}\right)$ in patients who underwent short segment posterior fixation. X-rays of implant in situ and immediate post-operative kyphotic angle of two patients, each who underwent long and short posterior fixation respectively shown (Figure 1).

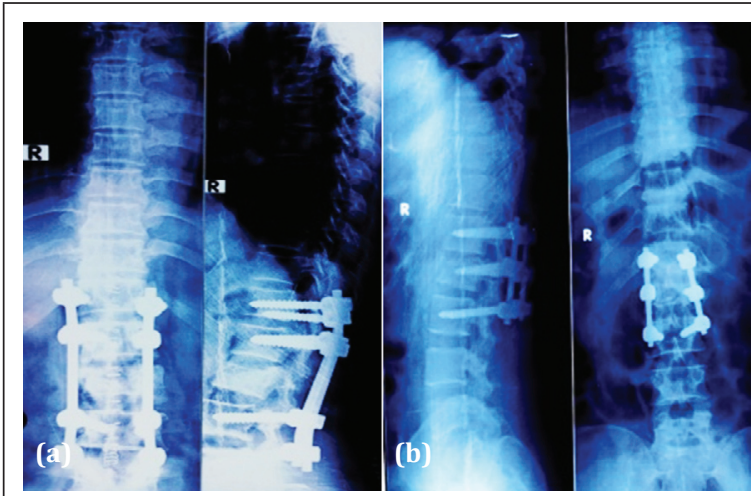

Figure 1a,b: Immediate post-operative X-ray of two patients who underwent long segment fixation and short segment fixation using posterior approach with pedicle screws. (a) L2 compression fracture (Long segment fixation), kyphotic angle: $7^{\circ}$; (b) L1 transverse fracture (Short segment fixation), kyphotic angle: $8^{\circ}$.

One year post-operative X-ray was taken and mean kyphotic angle was $8.41^{\circ}\left(6-11^{\circ}\right)$ in patient who underwent long segment posterior fixation whereas in those who underwent short segment fixation was found to be $9.25^{\circ}\left(6-12^{\circ}\right)$. The mean degrees of correction of kyphotic angle in immediate postoperative $\mathrm{x}$-rays in patients who underwent long segment fixation was $17.41^{\circ}\left(13-24^{\circ}\right)$ and $15^{\circ}$ $\left(12-21^{\circ}\right)$ via short segment. X-rays of implant in situ and one year post-operative kyphotic angle of two patients, each who underwent long and short posterior fixation respectively shown (Figure 2).

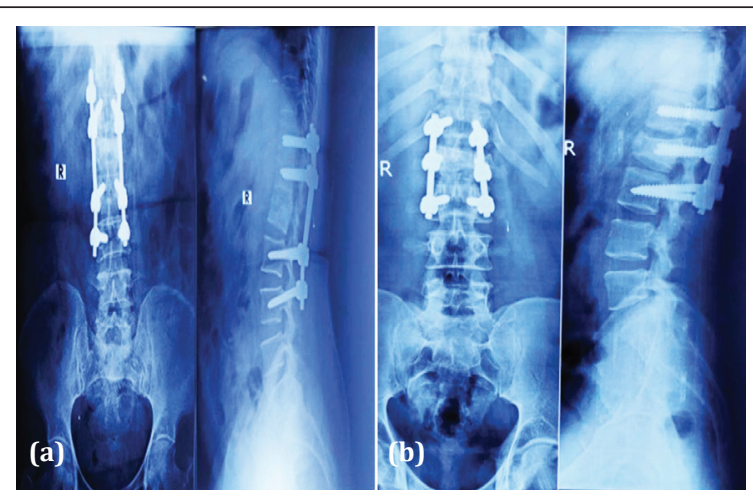

Figure 2a,b: One year post-operative follow up X-ray of same two patients who underwent long segment fixation and short segment fixation using posterior approach with pedicle screws. (a) L2 compression fracture (Long segment fixation), kyphotic angle: $8^{\circ}$; (b) L1 Transverse fracture (Short segment fixation), kyphotic angle: $11^{\circ}$.

Mean total loss of corrected kyphotic angle was $2.25^{\circ}$ $\left(1-4^{\circ}\right)$ in patients who underwent long segment fixation and $2.5^{\circ}\left(1-7^{\circ}\right)$ in patient who underwent short segment fixation (Table 3 ).

Table 3: Kyphotic angle parameters for both long segment fixation and short segment fixation using posterior approach with pedicle screws.

\begin{tabular}{|lll|}
\hline Parameters & Long segment & Short segment \\
\hline Pre-operative kyphotic angle & $18-30^{\circ}\left(\right.$ Mean $\left.=23.58^{\circ}\right)$ & $18-28^{\circ}\left(\mathrm{Mean}=21.75^{\circ}\right)$ \\
Immediate post-operative kyphotic angle & $4-9^{\circ}\left(\mathrm{Mean}=6.16^{\circ}\right)$ & $5-8^{\circ}\left(\mathrm{Mean}=6.75^{\circ}\right)$ \\
Post-operative kyphotic angle at one year follow up & $6-11^{\circ}\left(\mathrm{Mean}=8.41^{\circ}\right)$ & $6-12^{\circ}\left(\mathrm{Mean}=9.25^{\circ}\right)$ \\
Immediate post-operative kyphotic angle change & $13-24^{\circ}\left(\mathrm{Mean}=17.41^{\circ}\right)$ & $12-21^{\circ}\left(\mathrm{Mean}=15^{\circ}\right)$ \\
Post-operative kyphotic angle change at one year follow up & $11-21^{\circ}\left(\mathrm{Mean}=15.16^{\circ}\right)$ & $9-20^{\circ}\left(\mathrm{Mean}=12.5^{\circ}\right)$ \\
Loss of correction of kyphotic angle & $1-4^{\circ}($ mean=2.25 $)$ & $1-7^{\circ}\left(\mathrm{mean}=2.5^{\circ}\right)$ \\
\hline
\end{tabular}


Patients had no evidence of implant failure (construct bending, breakage, loosening or pullout). Calculation of percentage of initial kyphotic angle correction was done by the ratio of amount of correction in degrees to pre-operative kyphotic angle and was found to be more than $70 \%$ in $58.33 \%$ and less than $70 \%$ in $41.44 \%$ of patients who underwent long segment posterior fixation. And $66.66 \%$ in patient who underwent short segment posterior fixation it was found to be more than $70 \%$ in only $33.33 \%$ and less than 70\%in $66.66 \%$ (Table 4).

Table 4: Percentage initial kyphosis correction in long segment fixation and short segment fixation using posterior approach with pedicle screws.

\begin{tabular}{|lccc|}
\hline \multirow{2}{*}{ Fixation method } & \multicolumn{2}{c|}{ Kyphosis correction (\%) } & \multirow{2}{*}{ Total } \\
\cline { 2 - 3 } & $\geq 70$ & $<70$ & \\
\hline Long segment & $58.33 \%(7)$ & $41.66 \%(5)$ & 12 \\
Short segment & $37.5 \%(3)$ & $62.5 \%(5)$ & 8 \\
Total patients & 10 & 10 & 20 \\
\hline
\end{tabular}

Calculation of percentage of kyphotic angle correction loss was done by the ratio of amount of correction loss in degrees to initial kyphosis correction and mean correction loss was $13.06 \%$ in patients who underwent long segment posterior fixation and $17.19 \%$ in patients who underwent short segment posterior fixation (Table 5).

Table 5: Mean percentage kyphosis angle correction loss in long segment fixation and short segment fixation using posterior approach with pedicle screws.

\begin{tabular}{|ll|}
\hline Fixation method & Mean kyphosis correction loss (\%) \\
\hline Long segment & 13.06 \\
Short segment & 17.19 \\
\hline
\end{tabular}

\section{Discussion}

The results obtained were analysed using SPSS software version 19. Power of the study was 78.8\%. Mean age group of the patients in the study group was 29.8 years. Changes in the pre-operative, immediate post-operative and one year follow kyphotic angle among different age groups did not show significant differences $(p<0.4)$ Correction of kyphotic angles immediate post-operative and change or loss of kyphotic angle in one year follow up between males and female did not show significant correlation $(p<0.5)$. This could be due to the younger age group involved in the study, with chances of better cortical integrity and bone healing as compared to older patients with higher rates of osteoporosis as well understood by the literature. A study made on prevalence of osteoporosis in patients requiring spine surgery found that only $0.3 \%$ among 562 patients younger than 50 years had spinal osteoporosis and concluded by strongly recommending evaluation for osteoporosis in patients over 50 years [28]. Majority of the patients had AO type A2 (45\%) fractures followed by type A3 (35\%). The changes in immediate post-operative and change or loss of kyphotic angle in one year follow up showed no significant differences among the different type of fractures $(p<0.8)$. The mean degree of correction of the kyphotic angle immediate post operatively was found to be better in case of long segment fixation of lumbar vertebral fracture than that of short segment fixation. In a study, average kyphosis correction of $15^{\circ}$ was obtained using short segment posterior fixation by Mahar et al [15]. No statistical difference between the degrees of correction of initial kyphotic angle between long segment fixation and short segment posterior fixation in our study found $(\mathrm{p}<0.6)$ suggesting excellent immediate postoperative kyphotic angle correction in both these techniques. Similar result was found by Guven et al [14].

Method of fixation of the thoracolumbar vertebral fracture did not correlate with initial degree of kyphosis $(\mathrm{p}=0.4)$. Degree of correction loss at one year follow up was found to be statistically significant in short segment fixation $(\mathrm{p}<0.05)$. Our study showed that loss of kyphotic angle at one year follow up was statistically higher in case of short segment fixation than long segment fixation and found to be statistically significant $(p<0.005)$. Similar result was obtained by several studies $[29,30]$. Studies have shown that addition of pedicle screws at the level of the vertebral fracture to stiffen the construct by the splitting of the rod that extends from the top most screw to the lower most into two half lengthed parts. In short segment fixation, shorter rods between two points of fixation creates higher stiffness and stability but theoretically reduce the range of motion at bone-implant interface [31,32].

Short segment fixation limits the number of segments of the vertebrae to be instrumented to minimum, improves and restores the sagittal balance, stabilizes 
the fracture and avoids the motion segments of the lumbar vertebrae, i.e. mid and lower lumbar motion segments. One year post-operative follow up showed no significant differences functional outcomes in patients operated with long and short segment pedicle screw fixation in parameters such as pain, range of movements and neurological status or implant failure in radiography.

Decompression of the spinal canal, maintenance of the vertebral body height, alignment of the spine, restoration of the spinal canal, rigid fixation and early ambulation and prevention of further neurological injuries and to prevent progression of fixation kyphotic deformity is the goal of the posterior pedicle screw fixation, many studies have considered short segment pedicle screw fixation as standard method $[7,16,26,33-37]$ though no statistical difference in the stiffness of the construct between long segment fixation and short segment fixation constructs in a biomechanical study of L2 burst fractures was found in a study by Ann et al [21]. Mean percentage loss of kyphotic angle correction was higher in case of short segment fixation (17.19\%) as when compared to $(13.06 \%)$ patients who were operated with long segment fixation. This could be due to reduced initial correction of the kyphotic angle by short segment fixation. In our study, patients operated with neither long segment nor short segment fixation had any implant failure at one year post-operative follow up, although studies have showed chances of higher implant failure rate in short segment fixation methods [38].

This doesn't suggest that there are no chances of implant failure in either of the fixation methods. Successive follow up of patient would provide further insight to implant failure between these two fixation methods. $10^{\circ}$ or more loss of kyphotic angle correction is suggested to be the criteria of failure of implant by several studies [16, 26, 27, 33] which suggests proper planning, pre-operative preparation and experience of the surgeon plays a major role in outcomes of these studies. Rigid fixation of the fracture was better possible in case of short segment fixation, though our study shows more than $58 \%$ of cases with more than 70\% kyphotic angle correction compared to $33.3 \%$ in short segment fixation. In a study, Lee etal [39] declared that longsegment pedicle instrumentation can reduce implant failure rate, although it sacrifices additional motion segments of the thoracolumbar vertebrae and eventually reduces range of motion of the thoracolumbar vertebrae [23, 40]. A study done in 2018 concluded that the short segment fixation can maintain angle of kyphosis similar to that of long segment fixation for single level thoracolumbar fractures [41]. When analyzed, $50 \%$ of the study group was found to have more than $70 \%$ and less than $70 \%$ kyphotic angle correction respectively. We do acknowledge that some limitations exist in our study. Firstly, the study group is of 20 patients which can lead to bias. Association of parameters such as bone marrow density, personal habits, other systemic disorders, patient compliance post operatively to doctor's orders, self-medicating habits along with successive follow up and randomized control trials would give better insight and knowledge of the factual data in future.

\section{Conclusion}

The study concludes that long segment posterior fixation of thoracolumbar fracture shows better final outcome in the amount of correction of the kyphosis angle with lesser chance of loss of correction. The short segment fixation provides better rigid fixation at the site of fracture with increased range of motion at the thoracolumbar segment. Clinical outcomes bore no differences post operatively among patients operated with either of the technique. Short segment fixation can be chosen when the pedicles at the fractured level are intact, as in cases of compression fractures, owing to shorter duration of surgery and reduced risks and long segment fixation to be opted for better kyphotic angle correction, as in cases of burst fractures, where integrity of pedicles are lost. Randomised studies involving longer duration of follow ups would give a better insight to choose either long segment or short segment posterior fixation for thoracolumbar fractures using pedicle screws.

\section{Conflicts of interest}

Authors declare no conflicts of interest.

\section{References}

[1] Riggins RS, Kraus JF. The risk of neurological damage with fractures of the vertebrae. Journal of Trauma.1977; 17(2):126-133.

[2] Marvin RL. Fracture, dislocations, and fracture dislocation of spine, chapter 35. EdtCanale S. Terry Missouri, Mosby. 2003; 2(10):1597-1690. 
[3] Gunmann L. The treatment and rehabilitation of patients with injuries of spinal cord. In Cope 2; Edn: Medical history of the second world war: Surgery, London. 1953; His Majesty Stationary office.

[4] Heary RF, Salas S, Bono CM, Kumar S. Complication avoidance: thoracolumbar and lumbar burst fractures. Neurosurg Clin N Am. 2006; 17(3):377-388.

[5] Danisa OA, Shaffrey CI, Jane JA. Surgical approaches for correction of unstable thoracolumbar burst fracture: A retrospective analysis. J Neurosurgery. 1995; 83(6):977983.

[6] Roy-Camille R, Saillant G, Mazel C. Internal fixation of the lumbar spine with pedicle screw plating. Clin Orthop Relat Res. 1986; 203:7-17.

[7] Dick W, Kluger P, Magerl F, Woersdorfer 0, Zach G. A new device for internal fixation of thoracolumbar and lumbar spine fractures: the 'fixateurinterne'. Paraplegia. 1985; 23(4):225-232.

[8] Robert FM. The Biomechanics of Long versus Short Fixation for Thoracolumbar Spine Fractures. Lippincott Williams and wilkins,inc. Spine. 2006; 31(11):70-79.

[9] Aebi M, Etter C, Kehl T, Thalgott J. Stabilization of the lower thoracic and lumbar spine with the internal spinal skeletal fixation system. Indications, techniques, and first results of treatment. Spine. 1987; 12(6):544-551.

[10] Tezeren G, Kuru I. Posterior fixation of thoracolumbar burst fracture: short-segment pedicle fixation versus longsegment instrumentation. J Spinal Disord Tech. 2005; 18(6):485-488.

[11] Sapkas G, Kateros K, Papadakis SA, Brilakis E, Macheras G, et al. Treatment of un $\urcorner$ stable thoracolumbar burst fractures by indiาrect reduction and posterior stabilization: shortsegment versus long-segment stabiliza 7 tion. Open Orthop J. 2010; 4:7-13.

[12] Tabak AY, Gunay MC, Altay M, Turker HB. Effects of shortand long-segment posterior instrumentation on spinal canal remodeling in thoracolumbar vertebra burst fractures. Ulus Travma Acil Cerrahi Derg. 2011; 17(2):141-148.

[13] Moon MS, Choi WT, Moon YW, Kim YS, Moon JL. Stabilisation of fractured thoracic and lumbar spine with CotrelDubousset in strument. J OrthopSurg (Hong Kong). 2003; (11):59-66.

[14] Guven O, Kocaoglu B, Bezer M, Aydin N, Nalbantoglu U. The use of screw at the fracture level in the treatment of thoracolumbar burst fractures. J Spinal Disord Tech. 2009; (22):417-421.

[15] Mahar A, Kim C, Wedemeyer M, Mitsunaga L, Odell T, et al. Short-segment fixation of lumbar burst fractures using pedicle fixation at the level of the fracture. Spine. 2007; 32(14):1503-1507.

[16] Ahmet A, Emre A, Muharrem Y, Ali O, Adil S. Short- Segment Pedicle Instrumentation of Thoracolumbar Burst Fractures Does TranspedicularIntracorporeal Grafting Prevent Early Failure?. Spine. 2001; 26(2):213-217.

[17] Muller U, Ulrich B, John Sl, Othmar S. Treatment of thoracolumbar burst fractures without neurologic deficit by indirect reduction and posterior instrumentation: bisegmental stabilization with monosegmental fusion. Eur Spine J.1999; 8(4):284-289.

[18] Parker JW, Lane JR, Karaikovic EE, Gaines RW. Successful short-segmentinstrumentationand fusionfor thoracolumbar spine fractures: a consecutive 41/2-year series. Spine. 2000; 25(9):1157-1570.
[19] Gurr KR, McAfee PC, Shih C. Biomechanical analysis of anterior and posterior instrumentation systems after corpectomy: a calf-spine model. J Bone Joint Surg Am. 1988; 70(8):1182-1191.

[20] Gurr KR, McAfee PC, ShihC. Biomechanical analysis of posterior instrumentation systems after decompressive laminectomy: an unstable calf-spine model. J Bone Joint Surg Am. 1988; 70(5):680-691.

[21] An HS, Singh K, Vaccaro AR, Wang G, Yoshida H, et al. Biomechanical evaluation of contemporaryposterior spinal internal fixation configurations in an unstable burstfracture calf spine model. Spine.2004; 29(3):257-262.

[22] Ebelke DK, Asher MA, Neff JR, Kraker DP. Survivorship analysis of VSP spine instrumentation in the treatment of thoracolumbar and lumbar burst fractures. Spine. 1991; 16(8 suppl):428-492.

[23] Altay M, Ozkurt B, Aktekin CN, Ozturk AM, Dogan O, et al. Treatment of unstable thoracolumbar junction burst fractures with short- or long-segment posterior fixation in magerl type a fractures. Eur Spine J. 2007; 16(8):11451155.

[24] Akbarnia BA, Crandall DG, Burkus K, Matthews T. Use of long rods and a short ar-throdesis for burst fractures of the thoracolum $\neg$ bar spine. A long-term follow-up study. J Bone Joint Surg Am. 1994; 76(11):1629-1635.

[25] Cho DY, Lee WY, Sheu PC. Treatment of thoracolumbar burst fractures with polymethyl methacrylate vertebroplasty and short-segment pedicle screw fixation. Neurosurgery. 2003; 53(6):1354-1360.

[26] Kramer DL, Rodgers WB, Mansfield FL. Transpedicular instrumentation and short-segment fusion of thoracolumbar fractures: a prospective study using a single instrumentation system. J Orthop Trauma. 1995; 9(6):499-506.

[27] McCormack T, Karaikovic E, Gaines RW. The load sharing classification of spine fractures. Spine. 1994;19(15):17411744.

[28] Chin DK, Park JY, Yon YS, Kuh SU, Jin BH, et al. Prevalence of osteoporosis in patients requiring spine surgery: incidence and significance of osteoporosis in spine disease. Osteopor int. 2007; 18(9):1219-1224.

[29] Amr ES, Kaled S, Ahmed E. Comparison of long segment fixation versus short segment fixation with pedicle screws at the level of fracture in the management of thoracolumbar fractures. Egy Spine J. 2013; (5):47-52.

[30] Mohan NS, Sindhu B, Shankar GP. Functional outcome of short vs. long segment transpedicular fixation in thoracolumbar junction burst fractures-A comparative study. Int J Orth Sci. 2020; 6(2):312-318.

[31] Anekstein Y, Brosh T, Mirovsky Y: Intermediate screws in short segment pedicular fixation for thoracic and lumbar fractures: a biomechanical study. J Spinal Disord Tech. 2007; 20(1):72-77.

[32] Dick JC, Jones MP, Zdeblick TA, Kunz DN, Horton WC. A biomechanical comparison evaluating the use of intermediate screws and cross-linkage in lumbar pedicle fixation. J Spinal Disord. 1994; (5):402-407.

[33] McLain RF, Sparling E, Benson DR. Early failure of shortsegment pedicle instrumentation for thoracolumbar fractures.A preliminary report. JBone Joint Surg Am. 1993; 75(2):162-167.

[34] Mikles MR, Stchur RP, Graziano GP. Posterior Instrumentation for Thoracolumbar Fractures. J Am Acad Orthop Surg.2004; 12(6):424-435. 
[35] Aly TA. Short Segment versus Long Segment Pedicle Screws Fixation in Management of Thoracolumbar Burst Fractures: Meta-Analysis. Asian Spine J. 2017; 11(1):150-160.

[36] Rommens PM, Weyns F, Calenbergh FV, Goffin J, Broos PL. Mechanical performance of the Dick internal fixator: a clinical study of 75 patients. Eur Spine J. 1995; 4(2):104109.

[37] Rc S, Hb C. Posterior instrumentation and fusion for unstable fractures and fracture-dislocations of the thoracic and lumbar spine. A comparative study of three fixation devices in 70 patients. Spine (Phila Pa 1976).1993; 18(4):450-460.

[38] Speth MJ, Oner FC, Kadic MA, Klerk LW, Verbout AJ. Recurrent kyphosis after posterior stabilization of thoracolumbar fractures. 24 cases treated with a Dick internal fixator followed for 1.5-4 years. Acta Orthop Scand. 1995; 66(5):406-410.

[39] Lee S, Pandher D, Yoon K, Lee S, Oh KJ. The effect of postoperative immobilization on short-segment fixation withoutbone grafting for unstable fractures of thoracolumbar spine. Indian J Orthop. 2009; 43(2):197-204.

[40] Aebli N, Timm K, Patrick M, Krebs J. Short-segment posterior instrumentation combined with anterior spondylodesis using an autolongous rib graft in thoracolumbar burst fractures. Acta Orthop. 2014; 85(1):84-90.

[41] Sallam AM, Ghany WAA, Ali AK, Habib MA, Toubar AF, et al. Short-segment posterior fixation with index level screws versus long-segment posterior fixation for thoracolumbar spine fracture: angle of correction and pain. Egypt J Neurosurg. 2018; 33:11. 